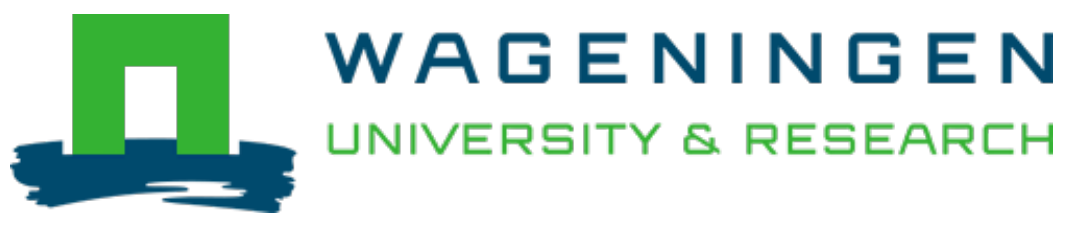

\title{
Effect of roasting and fermentation on viscosity of cereal-legume based food formulas.
}

\author{
Plant Foods for Human Nutrition \\ Wanink, J.F.; Vliet, T.; Nout, M.J.R. \\ https://doi.org/10.1007/bf01088763
}

This publication is made publicly available in the institutional repository of Wageningen University and Research, under the terms of article $25 \mathrm{fa}$ of the Dutch Copyright Act, also known as the Amendment Taverne. This has been done with explicit consent by the author.

Article 25 fa states that the author of a short scientific work funded either wholly or partially by Dutch public funds is entitled to make that work publicly available for no consideration following a reasonable period of time after the work was first published, provided that clear reference is made to the source of the first publication of the work.

This publication is distributed under The Association of Universities in the Netherlands (VSNU) 'Article $25 \mathrm{fa}$ implementation' project. In this project research outputs of researchers employed by Dutch Universities that comply with the legal requirements of Article $25 \mathrm{fa}$ of the Dutch Copyright Act are distributed online and free of cost or other barriers in institutional repositories. Research outputs are distributed six months after their first online publication in the original published version and with proper attribution to the source of the original publication.

You are permitted to download and use the publication for personal purposes. All rights remain with the author(s) and / or copyright owner(s) of this work. Any use of the publication or parts of it other than authorised under article $25 \mathrm{fa}$ of the Dutch Copyright act is prohibited. Wageningen University \& Research and the author(s) of this publication shall not be held responsible or liable for any damages resulting from your (re)use of this publication.

For questions regarding the public availability of this publication please contact openscience.library@wur.nl 


\title{
Effect of roasting and fermentation on viscosity of cereal-legume based food formulas
}

\author{
J.F. WANINK, T. VAN VLIET \& M.J.R. NOUT* \\ Department of Food Science, Agricultural University, Bomenweg 2, 6703 HD Wageningen, The \\ Netherlands (*author for correspondence)
}

Received 13 April 1993; accepted in revised form 2 August 1993

Key words: Accelerated natural lactic fermentation, Candida famata, Lactobacillus plantarum, Maize, pH, Roasting, Soya

\begin{abstract}
With the view of preparing semi-liquid weaning foods of high energy content, the influence of roasting (stationary hot air treatment) and fermentation (with natural and pure culture inocula) on the viscosity of maize-sorghum-soya porridges was investigated. Roasting resulted in porridges of significantly higher viscosity (cooked porridge cooled to $40^{\circ} \mathrm{C}$ ). Porridges made from the individual ingredients (maize, sorghum, soya) did not show this behaviour. Natural fermentation of mixed ingredients resulted in lower porridge viscosities (cooked porridge cooled to $40^{\circ} \mathrm{C}$, as well as hot-paste peak viscosity) when $\mathrm{pH}$ was $5.0-5.5$. At lower $\mathrm{pH}$ the viscosity of the final porridges increased. Fermentation experiments of individual ingredients inoculated with pure cultures of Lactobacillus plantarum and Candida famata lead to the conclusion that various factors contribute to the effect of fermentation on porridge viscosity. Porridges of minimum viscosity are obtained at $\mathrm{pH} 5.0-5.5$ corresponding with a moderate extent of fermentation. From a consumer safety point of view, it would be preferable to acidify to lower $\mathrm{pH}$ values $(\mathrm{pH}<4.5)$. If necessary, viscosity adjustments could be made using malted cereals.
\end{abstract}

\section{Introduction}

The use of weaning foods as an addition to breast feeding often starts at an age of 6-12 months. With the view of the development of weaning formulas from tropical food ingredients, mixtures of cereals and legumes can be used. These must supply adequate amounts of metabolizable energy and protein. Especially at an age of 9-12 months, the nutrient intake is limited by a combination of inadequate masticating and swallowing ability and small stomach capacity [1]. Consequently a higher energy and nutrient concentration is required in a weaning porridge.

At a body weight of $7 \mathrm{kgs}$, approximately $3500 \mathrm{~kJ}$ daily are required [2]. If e.g. $50 \%$ of the energy must be met by 3 feedings of $200 \mathrm{ml}$ in addition to breast milk, each feeding must provide about $600 \mathrm{~kJ}$. Considering that a dry formulated mix has an energetic value of ca. $16 \mathrm{~kJ} / \mathrm{g}$ dry solids, the weaning porridges should thus contain approximately $19 \%$ dry matter. Particularly if porridges are made from cereals and legumes, the products tend to be rather stiff and difficult to swallow for babies. Replacement of cereal by sugar or 
vegetable oil helps to reduce the viscosity but these ingredients are relatively expensive. Alternatively, the use of germinated (malted) cereals is effective in reducing the viscosity of gelatinised starchy gels [3]. Roasting and fermentation are operations which can be applied to reduce antinutritional factors and to increase bio-availability as well as microbiological safety [4]. Little is known about the effect of roasting on the viscosity of formulated porridges. Concerning the effect of fermentation on dry-milled cereals and legumes, reduction of the hot-paste Brabender peak viscosity of black gram (Phaseolus mungo) flour [5] and dry-milled maize [6], as well as increases for dry-milled maize [7, 8], were reported. The aim of this investigation was to evaluate the effect of roasting and natural lactic fermentation on the viscosity of high-energy multi-component porridges. Where relevant, comparisons were made with single ingredients.

\section{Materials and methods}

Materials. White sorghum (Sorghum bicolor) from Sudan and white dent maize (Zea mays) from Zimbabwe were obtained through Grano-Drente, the Netherlands. Abrasion-dehulled yellow seeded soya beans (Glycine max) from Brazil were obtained through V.O.F. Kleinjan, the Netherlands. Maize starch and sucrose were obtained from local supermarkets. Lactobacillus plantarum and Candida famata had been previously isolated from fermenting sorghum [9] and were grown and maintained on MRS (de Man, Rogosa and Sharpe) medium (Merck No. 10661, Darmstadt, Germany) and Malt extract (3\%) broth (Oxoid L39, UK).

Ingredients processing. Maize, sorghum and soya beans were cleaned by sieving and aspiration. Coarse grinding (particle size 1-2 $\mathrm{mm}$ ) was with a toothed disc mill (Condux type LV 15M, Condux-Werk, Wolfgang bei Hanau, Germany). Subsequent fine milling was carried out with a hammermill (Fritsch Pulverisette 14.702 , Germany) equipped with a $0.12 \mathrm{~mm}$ screen. Intermediate storage was in polythene bags at $7^{\circ} \mathrm{C}$.

Porridge composition. The multi-component dry porridge mix consisted of sorghum, maize, soya and sucrose (weight ratio 33:33:23:11) and contained $1635 \mathrm{~kJ}$ metabolizable energy per $100 \mathrm{~g}$. Using this mix, porridges of $19-20 \%$ dry matter content were made for viscosity assessment.

Roasting. A ventilated oven (BS250, Gallenkamp, UK) with air temperature of $230^{\circ} \mathrm{C}$ was used. The material to be roasted was spread as a mono-layer for kernels or as a $2 \mathrm{~mm}$ layer for coarsely ground material on non-perforated trays. Roasting periods were taken from the moment of introduction into the pre-heated oven. 
Natural fermentation. Accelerated natural lactic fermentation [10] was performed on the multi-component mix as follows. A mixture of finely milled sorghum, maize and soya beans (weight ratio 37:37:26) was mixed with an equal weight of tapwater. After inoculation with $10 \%(\mathrm{w} / \mathrm{w})$ of a stabilized enrichment culture on the same flour mixture, incubation followed at $30^{\circ} \mathrm{C}$ during 24 hours. At progressive stages of fermentation, samples were taken. Their $\mathrm{pH}$ was recorded, the required amount of sucrose and water was added and porridge was prepared (see below). In some cases, the fermented samples were neutralized with $2 \mathrm{~N} \mathrm{NaOH}$ to $\mathrm{pH} 6.30$ and subsequently made into porridge.

Fermentation with added pure culture inocula. Pure cultures of Lactobacillus plantarum and Candida famata were cultivated on MRS medium and Malt Extract Broth, respectively, for 24 hours at $30^{\circ} \mathrm{C}$. These cultures were used to inoculate $(2 \% \mathrm{v} / \mathrm{w})$ single ingredients (ground soya beans, ground maize) mixed with equal weights of tapwater. Commercial maize starch was tested as well. To provide fermentable substrate, filtered maize steepwater was used instead of tapwater to achieve a suspension of $20 \%$ dry matter content. The steepwater was obtained by soaking maize kernels in water at $7^{\circ} \mathrm{C}$ followed by filtration through muslin cloth. Fermentation of the inoculated ingredients, and sampling for porridge preparation was as described above.

Preparation of porridge. The ingredients (weights based on dry matter) required for $200 \mathrm{~g}$ porridge were mixed in a $250 \mathrm{ml}$ glass beaker. Cold water was added to make up to $200 \mathrm{~g}$ and a smooth batter was made prior to heating on an electric hotplate. The mixture was heated to $80^{\circ} \mathrm{C}$ within 10 minutes with continuous stirring. Heating continued for another 10 minutes after which the porridge was allowed to cool at room temperature for 1 hour to approximately $50^{\circ} \mathrm{C}$. Viscosity was measured at $40^{\circ} \mathrm{C}$, and dry matter content of cooked porridge was determined by oven-drying $\left(3\right.$ hours at $\left.105^{\circ} \mathrm{C}\right)$.

Viscosity determination. The viscosity of cooked porridges was determined with a Rotoviscosimeter (Haake Mess-Technik, Germany) using sample bowl ' $m$ V' and rotor ' $\mathrm{mV}$-III' both covered with emery paper (Norton, Brazil, Korn 80) in order to prevent slip between the measuring body and the porridges. The measuring body constants for recalculation of the set rotation speed $\% \mathrm{D}$ in the shear rate $\dot{\gamma}$ and of the measured torsion $\% \tau$ in the shear stress $\sigma$ were determined using two calibration fluids with a viscosity in the range of the porridges. The recalculation was done by $\dot{\gamma}=2.38 \% \mathrm{D}\left[\mathrm{s}^{-1}\right]$ and $\sigma=4.91 \% \tau$ [Pa]. From these, the apparent viscosity $\eta^{*}$ was calculated by $\eta^{*}=\sigma / \gamma$ [Pa.s]. All measurements were carried out at $\dot{\gamma}=1.1 \mathrm{~s}^{-1}$. The pasting behaviour was assessed in an Amylo-Viscograph (Brabender, Germany) using a measuring box of $500 \mathrm{cmg}$. A standard of $450 \mathrm{~g}$ suspension of ingredients in water was put in the mixing bowl and the temperature was increased to $90^{\circ} \mathrm{C}$ within 30 minutes, held at $90^{\circ} \mathrm{C}$ for 30 minutes and reduced to $50^{\circ} \mathrm{C}$ within 30 minutes 
according to the programme. The apparent viscosity was recorded in arbitrary Brabender units.

\section{Results and discussion}

Figure 1 illustrates the rheological behaviour of multi-component porridge with maize, sorghum, soya and sucrose having $20 \%$ dry matter content. It shows that this type of porridge is shear-thinning and somewhat thixotropic with a corresponding hysteresis in the shear stress as a function of shear rate. The porridge had a yield stress of about $20 \mathrm{~Pa}$ as determined from the residual stress after stopping. All further measurements were carried out at a shear rate $\dot{\gamma}=1.1 \mathrm{~s}^{-1}$, obtained by increasing the rotation speed.

In Table 1, the effect of roasting of dry ingredients on the apparent viscosity of resulting multi-component porridges is presented. With increasing extent of roasting, the resulting porridges have significantly higher viscosities. As can be expected on the basis of better heat transfer, roasting is more effective with fine than with coarse particles or with intact kernels.

Table 2 summarizes the effect of the same roasting treatments on separate coarsely milled ingredients which were subsequently made into single-ingredient porridges. We choose to prepare porridges of such dry matter contents so as to obtain apparent viscosity data of the same order of magnitude of those

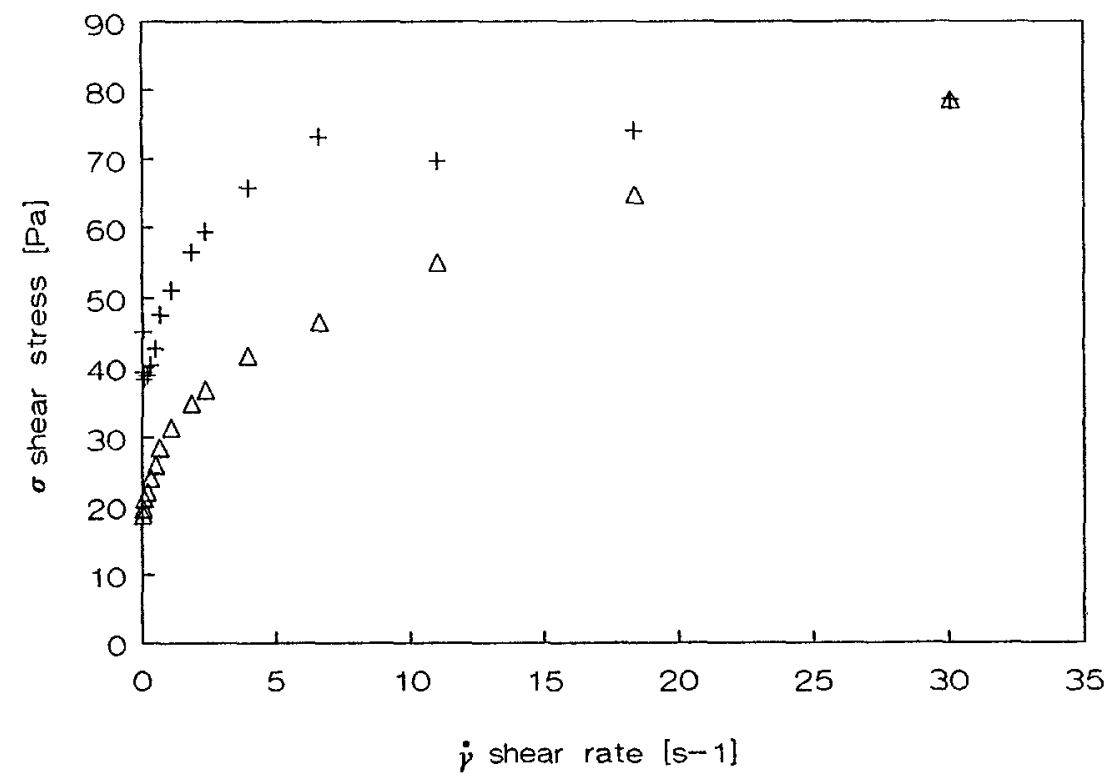

Fig. 1. Rheological behaviour of multi-component porridge $(20 \% \mathrm{w} / \mathrm{w}$ dry matter, non-roasted, non-fermented).

+ increasing shear rate.

$\Delta$ decreasing shear rate. 


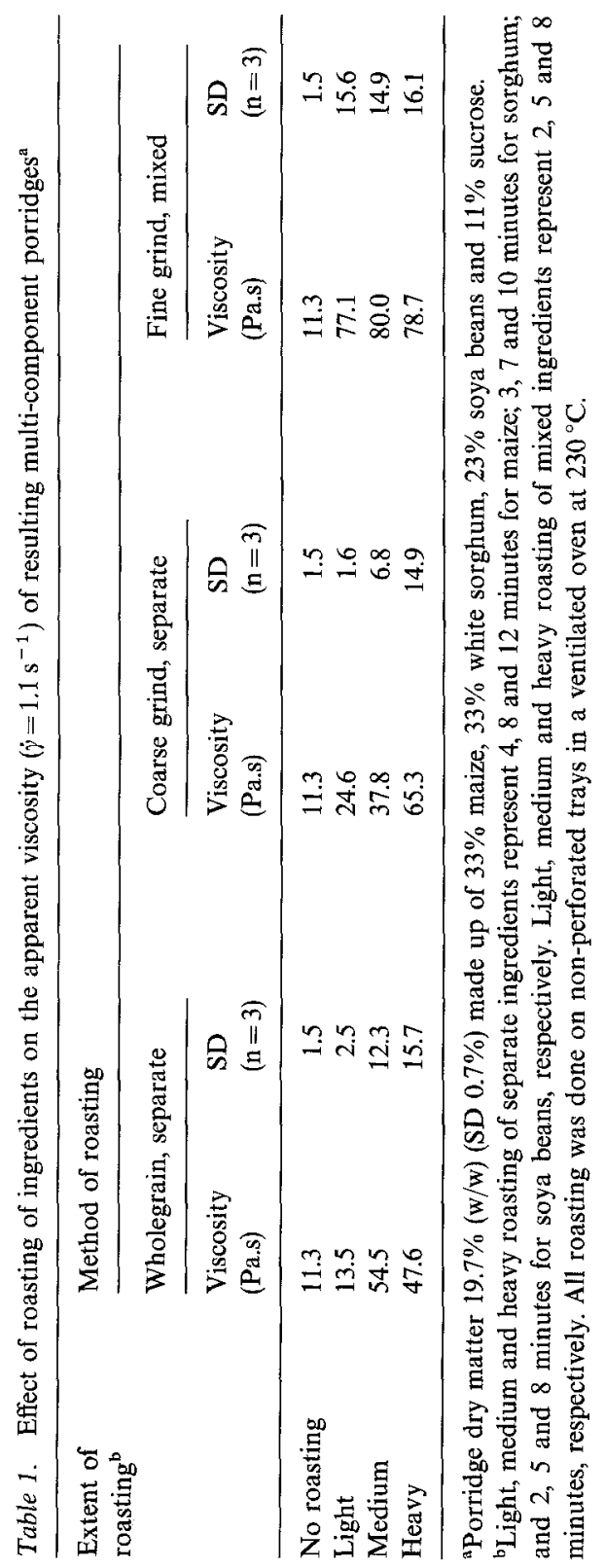




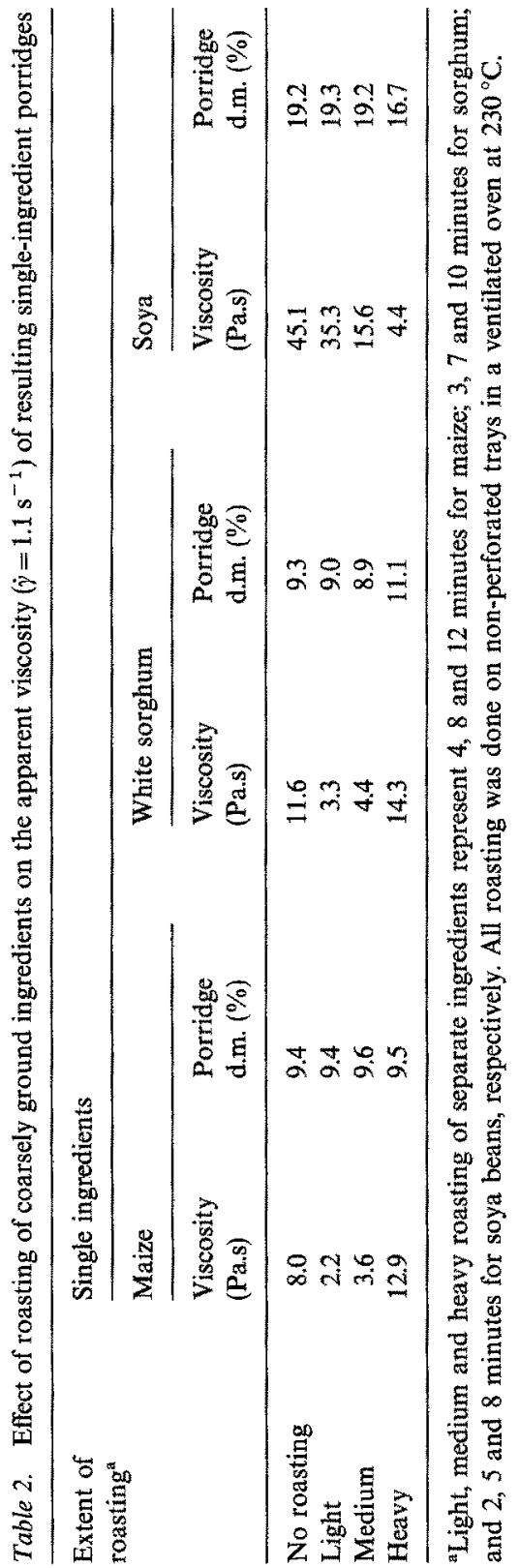


of the multi-component porridges. Although direct comparison of apparent viscosity data of Tables 1 and 2 is thus not possible, it can be clearly seen that the effects of roasting on the various ingredients differ considerably. With soya beans a significant apparent viscosity reduction was achieved whereas, the cereals gave some apparent viscosity reduction at light and medium roasting. Based on the differences between single- and multiple-component porridges (cf. Tables 1 and 2), we assume that some components (probably proteins) of the maize, sorghum or soya are affected, probably denatured, and after higher treatments maybe even partly aggregated by the heat treatment during roasting. These changes make the components concerned potentially more reactive for (physical) cross-linking with components of other ingredients during cooking of multi-component porridges.

The effects of natural lactic fermentation and of $\mathrm{pH}$ adjustment by $\mathrm{HCl}$ on the apparent viscosity of multi-component porridges are shown in Figure 2. Viscosity data obtained with the rotoviscosimeter (cooked porridge cooled to $40^{\circ} \mathrm{C}$, in Pa.s) and the visco-amylograph (peak viscosity, in Brabender Units) show similar trends. Depending on the extent of fermentation, the apparent viscosity is at first reduced compared to the non-fermented mixture. Minimum viscosities were observed at approximately $\mathrm{pH} 5.0-5.5$, followed by gradual viscosity increase with lowering $\mathrm{pH}$. When the $\mathrm{pH}$ of non-fermented ingredient mixtures were adjusted before cooking the porridge, a similar trend in apparent

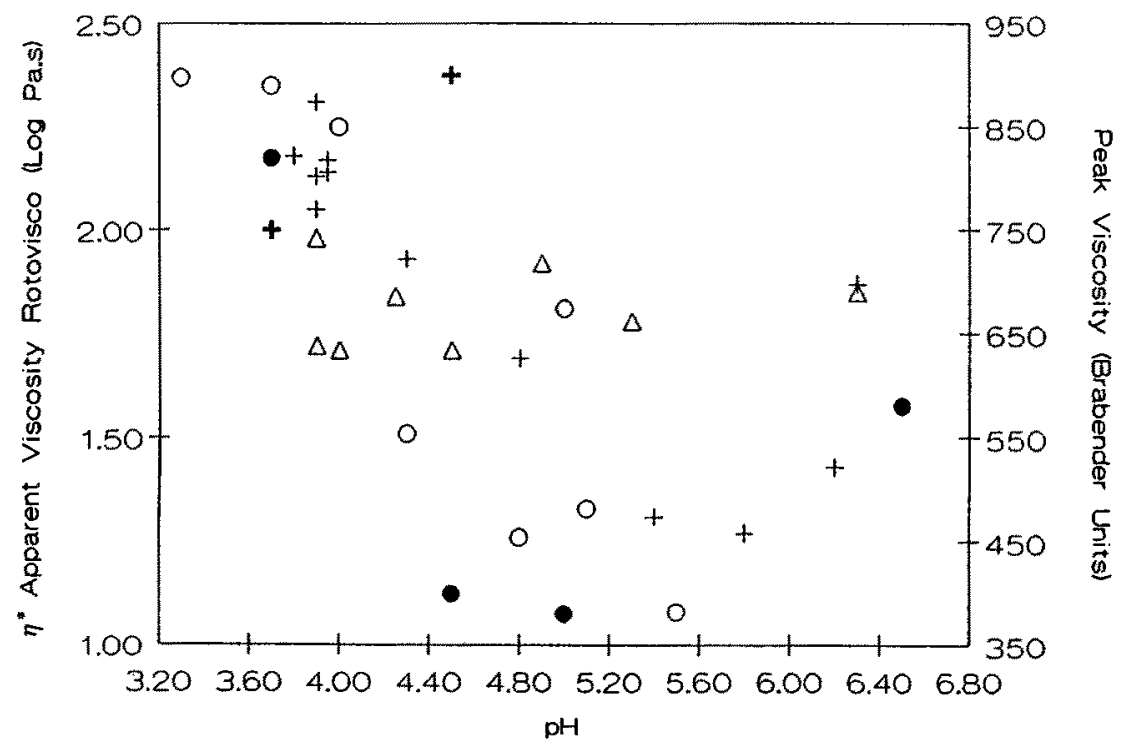

Fig. 2. Effect of natural lactic fermentation and $\mathrm{pH}$ on viscosity of multi-component porridge $(19.2 \pm 0.6 \% \mathrm{w} / \mathrm{w}$ dry matter $)$

$\mathrm{pH}$ achieved by natural lactic fermentation (+ Rotoviscometer, + Amylo-Viscograph);

fermented nntil $\mathrm{pH}$ indicated, followed by neutralization to $\mathrm{pH} 6.3$ prior to porridge cooking ( $\triangle$ Rotoviscometer);

$\mathrm{pH}$ adjusted with $\mathrm{HCl}$ (non-fermented) (O Rotoviscometer,

Amylo-Viscograph). 
viscosity as a function of $\mathrm{pH}$ was observed. When fermented ingredients were neutralized to the initial $\mathrm{pH}(6.3)$ prior to cooking, there were no significant viscosity effects. This implies that the effect of fermentation on viscosity could be ascribed to direct or indirect effects of $\mathrm{pH}$ resulting from fermentative acidification.

Table 3 summarizes data obtained with pure culture fermentation of single ingredients. Maize starch was included to compare with maize. A decrease of the maize starch $\mathrm{pH}$ before porridge preparation results in slightly reduced apparent viscosity of the cooked paste. Such a thinning may be caused by a slight acid hydrolysis during porridge cooking at a low $\mathrm{pH}[6,11]$. However, we found increased viscosities in fermented maize which must consequently, be associated with it's non-starch fraction. Fermentation of soya with the yeast Candida famata does hardly result in $\mathrm{pH}$ change nor in viscosity. On the other hand, in maize the $\mathrm{pH}$ decreased considerably with a corresponding viscosity increase. After neutralization the viscosity was of the same order of magnitude as the non-fermented control. Maize starch was also acidified by C. famata, the resulting apparent viscosity was clearly lower than of the non-fermented acidified paste. These data confirm that the paste viscosity of the maize starch fraction can be reduced somewhat by cooking at lower $\mathrm{pH}$, and more effectively by organisms able to degrade starch, e.g. C. famata [12].

Lactobacillus plantarum is not able to degrade starch. This may have contributed to the paste viscosities of maize starch which were slightly higher compared to the non-fermented control. Both soya and maize were acidified by $L$. plantarum and this resulted in significant viscosity increases. The viscosity effect appears to be stronger in soya (cf. ' $L$. plantarum' with ' $L$. plantarum neutralized'). As soya does not contain significant quantities of starch, we hypothesize that proteins play the most important role by increasing the viscosity at lower $\mathrm{pH}$ values. Irrespective of $\mathrm{pH}, L$. plantarum has a viscosity increasing effect on maize (cf. 'neutralized' with 'non-fermented'). This effect was observed to a lesser extent in maize starch and is possibly caused by the assimilation of non-starch solids by $L$. plantarum which results in increased starch content of the dry matter [7]. Another factor resulting in higher viscosity could be the gradual degradation of the endosperm matrix in which the starch granules are embedded. Conglomerates of starch granules cemented by matrix material will be of limited swelling capacity. Upon degradation of the matrix, the number of individual starch granules will increase, and so will the viscosity.

On the basis of the above data and those reported elsewhere [5-8], we conclude that acid fermentation of dry-milled mixtures of maize, sorghum and soya has at first a viscosity-reducing effect at $\mathrm{pH}$ 5.0-5.5. Although an increased viscosity might be expected because the starch content in the dry matter has increased somewhat, the actual decrease probably results from the maximum activity of grain $\alpha$-amylase at this $\mathrm{pH}$-level as well as from changes in protein conformation with $\mathrm{pH}$. At extended fermentation $(\mathrm{pH}<4.5)$ the starch content of the dry matter may have increased somewhat more, grain 


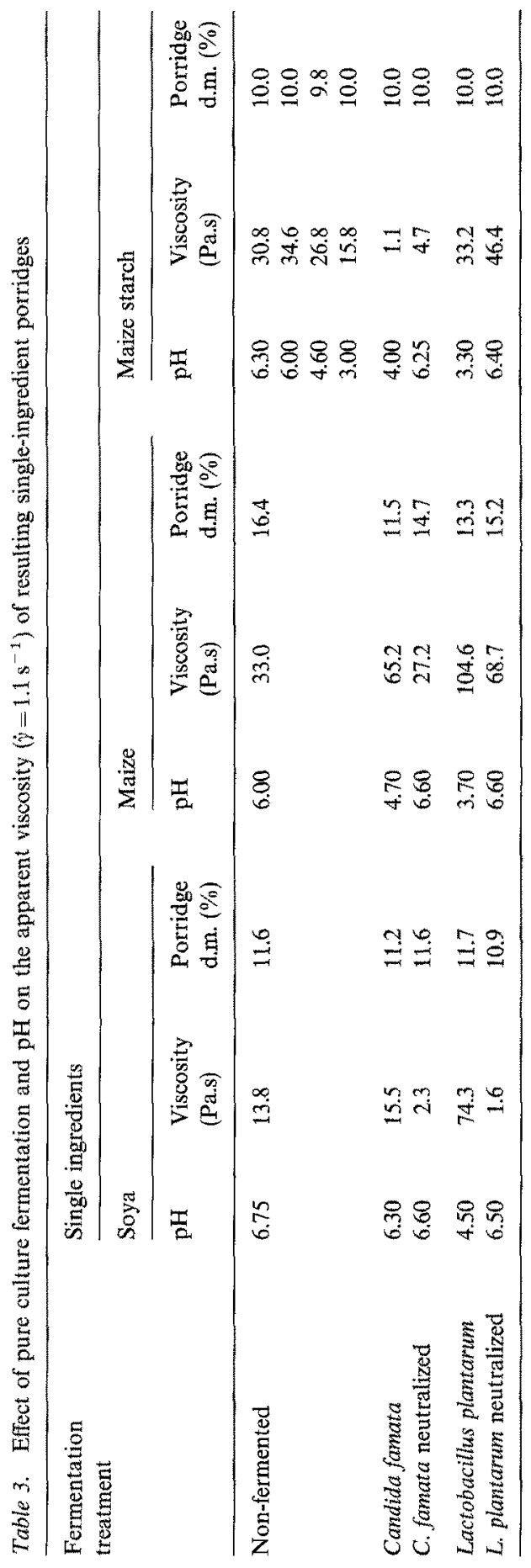


$\alpha$-amylase is inhibited and probably the main factor aggregation of the protein molecules during cooking increases as the $\mathrm{pH}$ approaches their iso-electric point. All factors together result in a significant increase of the peak viscosity. The only factor restraining the viscosity increase would be some acid hydrolysis of starch resulting in some thinning of the starch gel.

In conclusion, it appears that roasting as applied is not a suitable method for reduction of dietary bulk. On the other hand, a moderate extent of souring to $\mathrm{pH}$ 5.0-5.5 leads to significantly less viscous porridges. However, such level of acidity is inadequate to achieve microbiological stability [13]. It would therefore seem more appropriate to ferment to a minimum $\mathrm{pH}$ for hygienic safety and to apply malted grain [3] during porridge preparation for viscosity adjustment.

\section{References}

1. Waterlow J, Payne PR (1975) The protein gap. Nature (London) 258: 113-117.

2. Hiel AMM (1984) Young children and supplementary feeding programmes: A feld guide for the use of local foods and dried skim milk in Africa. Wageningen: The Netherlands Nutrition Foundation.

3. Malleshi NG, Desikachar HSR (1988) Reducing the paste viscosity (dietary bulk) of roller dried weaning foods using malt flour or fungal amylase. J Food Sci Technol (India) 25: 1-3.

4. Nout MJR (1993) Processed weaning foods for tropical climates. Int J Food Sci Nutr 43: 213-221.

5. Changala Reddy G, Susheelamma NS, Tharanathan RN (1989) Viscosity pattern of native and fermented black gram flour and starch dispersions. Starch/Stärke 41: 84-88.

6. Mbugua SK (1987) The nutritional and fermentation characteristics of uji produced from dry milled maize flour (unga baridi) and whole wet milled maize. Chem Mikrobiol Technol Lebens 10: $154-161$.

7. Adeyemi IA, Beckley O (1986) Effect of period of maize fermentation and souring on chemical properties and amylograph pasting viscosity of ogi. J Cereal Sci 4: 353-360.

8. Okoli EC, Adeyemi IA (1989) Manufacturing of ogi from malted (germinated) corn (Zea mays): Evaluation of chemical, pasting and sensory properties. J Food Sci 54: 971-973.

9. Nout MJR (1991) Ecology of accelerated natural lactic fermentation of sorghum-based infant food formulas. Int J Food Microbiol 12: 217-224.

10. Nout MJR, Rombouts FM, Hautvast JGAJ (1989a) Accelerated natural lactic fermentation of infant food formulations. Food Nutr Bull 11: 65-73.

11. Fennema OR (1985) Food chemistry, 2nd ed, revised and expanded. New York Basel: Marcel Dekker.

12. Lodder $\mathbf{J}(1970)$ The yeasts: A taxonomic study. Amsterdam: North-Holland Publ. Comp.

13. Nout MJR, Rombouts FM, Havelaar A (1989b) Effect of accelerated natural lactic fermentation of infant food ingredients on some pathogenic micro-organisms. Int J Food Microbiol 8: $351-361$. 